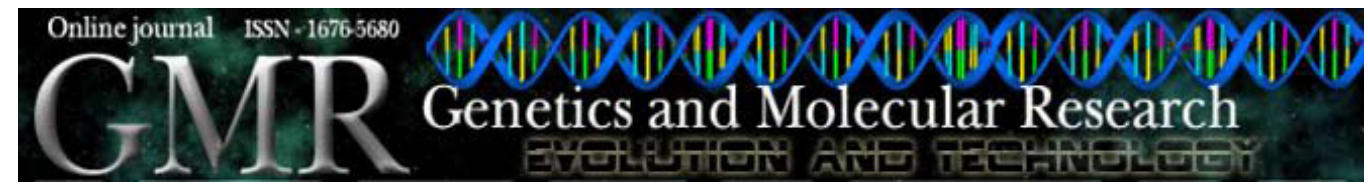

\title{
Genetic diversity in populations of the viper Bothrops moojeni Hoge, 1966 in Central Brazil using RAPD markers
}

\author{
N.C.L. Dutra ${ }^{1}$, M.P.C. Telles ${ }^{2}$, D.L. Dutra ${ }^{3}$ and N.J. Silva Júnior ${ }^{4}$ \\ ${ }^{1}$ Laboratório de Genética Animal, Universidade Federal do Amazonas, \\ Manaus, AM, Brasil \\ ${ }^{2}$ Departamento de Biologia, Laboratório de Genética and Biodiversidade, \\ MCAS/MGene/Zootecnia, Universidade Católica de Goiás, Goiânia, GO, Brasil \\ ${ }^{3}$ Mestrado em Biologia de Água doce e Pesca Interior, \\ Instituto Nacional de Pesquisas da Amazônia, Manaus, AM, Brasil \\ ${ }^{4}$ Mestrado em Ciências Ambientais e Saúde, Universidade Católica de Goiás, \\ Goiânia, GO, Brasil
}

Corresponding author: N.C.L. Dutra

E-mail: nicolecristina@yahoo.com.br

Genet. Mol. Res. 7 (3): 603-613 (2008)

Received May 2, 2007

Accepted February 18, 2008

Published July 8, 2008

ABSTRACT. Bothrops moojeni is an abundant venomous snake responsible for most of the snakebite cases in the Central region of Brazil and as a result of the anthropogenic habitat disturbance, such as the increase in extensive farming, the range of $B$. moojeni has been greatly fragmented. Here, we obtained genomic DNA from a total of 75 snakes belonging to four populations. Genetic variability evaluated for five RAPD primers was low $(\mathrm{He}=0.20)$ and was not spatially structured. We found evidence of significant genetic divergence among $B$. moojeni populations that were isolated $\left(\Phi_{\mathrm{ST}}\right.$ values of 0.21 and 0.25$)$, while populations more proximal exhibited less divergence $\left(\Phi_{\mathrm{ST}}\right.$ values of 0.04 and 0.08$)$. We found only moderate divergence $\left(\Phi_{\mathrm{ST}}\right.$ value of 0.12$)$ between two populations greatly isolated ( $851.83 \mathrm{~km}$ apart) along with great differentiation $(0.24)$ between two proximal populations (290 km apart). Even though these populations are close to each other, they occur in an urbanized area that is almost completely covered by extensive crops, representing an obstruc- 
tion to the mobility of this viper. Molecular variance analysis (AMOVA) showed some degree of subdivision in these populations, with a $\Phi_{\mathrm{ST}}$ value of 0.16 , significant to the level of $1 \%$ by 1000 random permutations. We also performed a Bayesian analysis that confirmed the AMOVA results and found a value of $\theta^{\mathrm{B}}=0.14$ and an $f=0.27$, suggesting a high level of endogamy. This is the first study that characterizes genetic variability for this important species of the Bothrops genus, and our data are of significant importance in terms of classifying populations in relation to their conservational value and management strategies. Thus, given the high levels of population structure found in this case, we recommend sampling as many populations as possible to maximize the genetic variability to be preserved when aiming for in situ conservation. The same should be done to perform samplings toward ex situ conservation.

Key words: Bothrops moojeni; Vipers; Genetic variability; RAPD; Conservation genetics; Genetic structure

\section{INTRODUCTION}

Evaluating genetic diversity and population structure of populations may be critical to define strategies for long-term conservation (Frankham et al., 2004). However, snakes are usually poorly represented in studies of conservation genetics, and particularly, some important species of the Bothrops genus have never been studied before. The "caissaca" (B. moojeni) for example, is an important species because it plays a significant role as secondary predators, controlling populations of small mammals (some of them considered plagues in crop areas), birds, lizards, frogs (Nogueira et al., 2003; Campbell and Lamar, 2004). The venom of this viper has many uses in human health, since it is a complex combination of proteins with biological activities that have potential use as models for the development of new pharmaceutical products. In fact, most studies that concern this snake and the Bothrops genus are related to the pharmaceutical industry.

\section{Large populations have a greater genetic variation and a decreased probability of inbreeding depression}

The effects of inbreeding are found in a great variety of animals, including snakes (Hartl, 2000; Frankham et al., 2003, 2004; Beebee and Rowe, 2004). Indeed, in a small and inbreeding population of Vipera berus in Switzerland, females had a reduction in offspring number and a higher rate of deformities in juveniles (Madsen et al., 1996). Újvári et al. (2002), using data provided by an RFLP marker, also evaluated and compared the genetic diversity of small populations of the viper Vipera ursinii rakosiensis from Hungary with large populations of a related subspecies (Vipera ursinii renardi) from Ukraine. These papers report that the habitat fragmentation to which populations are submitted may lead to a degree of isolation that could increase genetic differentiation, contributing to a decrease in population size and causing inbreeding depression in the long term (Stow and Briscoe, 2005).

Habitat fragmentation caused by urbanization and increase of crop areas has led to a great transformation of the Cerrado's landscape, accelerating the process of extinc- 
tion of many species. As a consequence, many habitats are fragmented and many species are disappearing (Galinkin, 2003; Klink and Machado, 2005). Despite all these facts, there are no vipers on the Official Brazilian List of Endangered Reptiles (IBAMA, 2003) for the Cerrado area. This is probably not because there are no species of vipers at risk or vulnerable to extinction, but due to the lack of studies concerning native species of the Brazilian Cerrado. At the same time, the genetic analysis of some relatively abundant species, such as the "caissaca" (Bothrops moojeni), may be useful in understanding the effects of habitat fragmentation and habitat loss in the Cerrado, even though the persistence of such species may not be directly affected by these effects (Telles et al., 2007).

Molecular markers can be used as a powerful tool to help develop efficient programs of conservation, because they provide information about the diversity and genetic structure of populations, the degree of gene flow, and the reproductive and mating systems (Petit et al., 1998; Frankham et al., 2004). The aim of the present study was to evaluate the genetic variability of B. moojeni populations in the Brazilian Cerrado, and to assess their divergence in genetic structure. We used RAPDs (random amplified polymorphic DNA) to determine the genetic diversity within and among populations of $B$. moojeni. The RAPD technique has been used as a successful tool in other population genetic studies of snakes (Prior et al., 1997; Jaggi et al., 2000).

\section{MATERIAL AND METHODS}

The "caissaca" is a venomous, viviparous snake whose length can reach $1.50 \mathrm{~m}$, is mainly nocturnal and is active more often in the course of the warmest and wettest months - from October to April. The reproductive cycle of this species is seasonal, and females give birth in the rainy season during the months of December and January (Nogueira et al., 2003).

The populations were collected in three locations in Goiás (GO) State and one in Mato Grosso (MT) State (Table 1). Some populations analyzed here (Minaçu and Sonora) were collected during fauna rescue programs and thus represent populations that have suffered the complete destruction of their habitats in order to build dams for hydroelectric power supply. On the other hand, population 3 (Goiânia-GO) was collected in an urbanized area, whereas population 4 (Jataí$\mathrm{GO}$ ) was collected in an urbanized area surrounded by farmlands. All of these individuals were obtained according to the availability in the Núcleo Regional de Ofiologia de Goiás.

\begin{tabular}{|c|c|c|c|}
\hline Sampled site & $\mathrm{N}$ & Latitude & Longitude \\
\hline 1. Sonora (MS) & 33 & $17^{\circ} 34^{\prime} 37^{\prime \prime}$ & $54^{\circ} 45^{\prime} 28^{\prime \prime}$ \\
\hline 2. Minaçu (GO) & 28 & $13^{\circ} 31^{\prime} 59^{\prime \prime}$ & $48^{\circ} 13^{\prime} 12^{\prime \prime}$ \\
\hline 3. Goiânia (GO) & 7 & $16^{\circ} 40^{\prime} 43^{\prime \prime}$ & $49^{\circ} 15^{\prime} 14^{\prime \prime}$ \\
\hline 4. Jataí (GO) & 7 & $17^{\circ} 52^{\prime} 53^{\prime \prime}$ & $51^{\circ} 42^{\prime} 52^{\prime \prime}$ \\
\hline
\end{tabular}

\section{Molecular data}

Blood samples (approximately 10 to $50 \mu \mathrm{L}$ ) of the snakes were obtained from the tail vein. Genomic DNA was extracted following exactly the protocol of Amersham Phar- 
macia Biotech ${ }^{\mathrm{TM}}$ blood purification kit. Five RAPD primers (Operon) previously selected with reliable and distinctly defined bands were used to generate the RAPD profiles and PCR amplifications (OPB-18, OPP-15, OPP-16, OPP-04, OPP-06). Amplification reactions were performed in $12 \mu \mathrm{L}$ containing $2 \mu \mathrm{L}$ genomic DNA $(\sim 3 \mathrm{ng} / \mu \mathrm{L}), 1.18 \mu \mathrm{L}$ primer $(\sim 10 \mathrm{ng} / \mu \mathrm{L}), 1.52 \mu \mathrm{L}$ buffer $(10 \mathrm{X}), 0.46 \mu \mathrm{L} \mathrm{MgCl}_{2}(50 \mathrm{mM}), 1.22 \mu \mathrm{L} \mathrm{dNTP}(2.5 \mathrm{mM}), 0.12$ $\mu \mathrm{L}$ Taq polymerase ( 5 units $/ \mu \mathrm{L}$ - provided by Amersham Pharmacia Biotech ${ }^{\mathrm{TM}}$ ), and $5.5 \mu \mathrm{L}$ Milli-Q $\mathrm{H}_{2} \mathrm{O}$. The reaction was then carried out in a PTC-100 thermal cycler (MJ Research) that was programmed for 40 cycles of $3 \mathrm{~min}$ at $96^{\circ} \mathrm{C}, 1 \mathrm{~min}$ at $92^{\circ} \mathrm{C}, 1 \mathrm{~min}$ at $37^{\circ} \mathrm{C}$, and $1 \mathrm{~min}$ at $71^{\circ} \mathrm{C}$, and with a final step of $3 \mathrm{~min}$ at $72^{\circ} \mathrm{C}$. The electrophoresis was performed on a $1.2 \%$ agarose gel which was stained with ethidium bromide, destained in water and visualized in ultraviolet light. The profiles were photographed and then scored for the presence or absence of fragments (1/0). To identify the size of DNA fragments a 100-bp ladder provided by Invitrogen ${ }^{\mathrm{TM}}$ was run together with the RAPD products.

\section{Statistical analyses}

We used RAPD profiles to estimate the allele frequencies based on Lynch and Milligan's (1994) method which allows one to calculate parameters in populations, under two basic assumptions: 1) The bands must be unequivocally identified on the gel and each band can be related to a locus with two alleles, considering that the dominant character (presence of bands) of the marker prevents the distinction between the heterozygote and homozygote genotypes; 2) populations must be in Hardy-Weinberg equilibrium. The frequency of the null allele (absence of bands) is estimated and then used to determine genetic diversity for each population and for the population subdivision (Nei, 1973), as suggested by Weir (1996) and Alfenas (1998).

We also performed two additional analyses to evaluate population structure (i.e., population divergence). An analysis of molecular variance (AMOVA; Excoffier et al., 1992) was used to assess the patterns of genetic structure. In this method, the distance among and within the local populations is partitioned, a strategy similar to that one used in a classical analysis of variance. AMOVA computes the components of variance from a Euclidean matrix of squared molecular distances between pairs of observations using RAPD bands. The component of interpopulation variance is obtained by equations from the proportion of genetic diversity among populations and then estimated by the $\Phi_{\mathrm{ST}}$ statistics, and the significance of this estimate was tested against the null hypothesis of no interpopulation variation by 1000 random permutations using TFPGA 1.3 (Miller, 1997). The $\Phi_{\mathrm{ST}}$ was also estimated between pairs of local populations, providing an explicit estimate of genetic divergence among local populations to be further used for spatial analyses.

Still aiming to estimate the genetic divergence of these populations, we used the software HICKORY, version 1.0 (Holsinger and Lewis, 2003) to perform an analogous analysis of the $\mathrm{F}$ statistics ( $\theta^{\mathrm{B}}$ estimator), the Bayesian approach proposed by Holsinger (1999). Data generated by dominant markers can be better estimated, and for this evaluation provide a more direct estimation of the relative magnitude of population divergence, and the inbreeding coefficient is given by $f$. Markov Chain Monte Carlo simulation was used to approximate numerically the a posteriori distribution of the estimator $\theta^{\mathrm{B}}$. This 
software allows the calculation of four different models: Full, $f=0, \theta^{\mathrm{B}}=0$ and $f$ free. In the full model, $\theta^{\mathrm{B}}$ and $f$ are calculated and two other models can assume $\theta^{\mathrm{B}}$ or $f$ equal to zero. In the last model, $f$ is free to vary, for estimates of $f$ based on dominant markers are usually strongly biased. All models were compared using the deviant information criterion (DIC) (Holsinger, 1999; Holsinger et al., 2002; Spiegelhalter et al., 2002; Holsinger and Wallace, 2004).

The genetic distance matrix from AMOVA was used in the cluster analysis UPGMA (unweighted pair-group method by arithmetic averages) often used to represent multivariate genetic distances and allows a classification of the populations in a hierarchical clustering represented by a dendrogram. The validity of this dendrogram was tested using the cophenetic correlation, which is the correlation between the original genetic distances and the distances among the populations in the UPGMA clustering (Manly, 1997). To analyze the patterns of spatial variation in a multivariate context, the correlation coefficient was also estimated between the matrices of genetic distances and the geographic distances among the populations, and in this case it can be tested by Monte Carlo (randomization) procedures (Mantel test; see Smouse et al., 1986; Manly, 1986, 1997; Epperson, 2003). In the present study, 5000 randomizations were used to test the significance of the matrix correlations.

\section{RESULTS}

All four populations displayed a low genetic variability according to the five RAPD primers used to analyze the 75 individuals. Considering each primer, the number of loci ranged from 9 to 18, with a total of 59 loci in the four populations (Table 2).

$\begin{aligned} & \text { Table 2. Relation of primers, their base sequences and the number of loci (NL) obtained in all four populations } \\
& \text { of Bothrops moojeni. }\end{aligned}$
\begin{tabular}{lcc}
\hline Primer & Sequence & NL \\
\hline OPB-18 & C C A C A G C A G T & 18 \\
OPP-15 & G G A A G C C A A C & 9 \\
OPP-16 & C C A A G C T G C C & 9 \\
OPP-04 & G T G T C T C A G G & 11 \\
OPP-06 & G T G G G C T G A C & 12 \\
Total & & 59 \\
\hline
\end{tabular}

We tested 79 primers and selected five that produced distinct band patterns. The percent of polymorphic loci ranged from 35 to $69 \%$ when we considered all local populations, with an average of $81 \%$ polymorphism (Table 3). Genetic diversity (Nei, 1973) was calculated based on five RAPD loci for the four populations, considering all loci simultaneously in the 75 individuals, and ranged from 0 to 0.5 . When this genetic diversity was analyzed for each population, we observed a variation from 0.10 and 0.17 , with an average of 0.20 (Table 3). Population 4 (Jataí-GO) revealed the lowest level of heterozygosity (0.10) among all populations, although population 3 (Goiânia-GO) showed a similar level (0.12). Population 1 (Sonora-MS) had a heterozygosity of 0.17 , whereas population 2 (Minaçu-GO) showed the highest value of 
heterozygosity (0.19). The highest expected value for genetic diversity when analyzing one locus with two alleles was $0.5 ; B$. moojeni, hence, had a low genetic diversity, for it had less than half of the expected value.

Table 3. Genetic diversity in the 59 RAPD loci in the four populations of Bothrops moojeni in Central Brazil; expected heterozygosity $(\mathrm{He})$, sample size $(\mathrm{N})$, number of polymorphic loci (NPL), and percent of polymorphic loci (\%PL).

\begin{tabular}{lcccc}
\hline Population & He (Nei) & N & NPL & $\%$ PL \\
\hline 1. Sonora (MS) & 0.17 & 33 & 41 & 69.5 \\
2. Minaçu (GO) & 0.19 & 28 & 38 & 64.4 \\
3. Goiânia (GO) & 0.12 & 7 & 25 & 42.4 \\
4. Jataí (GO) & 0.10 & 7 & 21 & 35.6 \\
Global & 0.20 & 18 & 48 & 81.3 \\
\hline
\end{tabular}

The AMOVA showed some degree of genetic structure in these populations, with a $\Phi_{\mathrm{ST}}$ value 0.16 , significant to the level of $1 \%$ by 1000 random permutations; thus, we can reject the null hypothesis of panmixia. It also showed that the within-population genetic diversity accounted for $83.7 \%$ and the among-population variability $16.3 \%$ of the total variance (Table 4 ), which could indicate a process of reduction in the rate of gene flow among the populations.

\begin{tabular}{|c|c|c|c|}
\hline Source of variation & d.f. & Sum of squares & $\%$ of variation \\
\hline Among populations & 3 & 53.4 & 16.30 \\
\hline Within populations & 71 & 303.7 & 83.70 \\
\hline Total & 74 & 357.1 & \\
\hline
\end{tabular}

d.f. $=$ degrees of freedom.

The coefficient of differentiation estimated for all pairs of populations (Table 5) ranged from 0.04 to 0.25 (Table 5), and the clustering of these distances using UPGMA reflects the spatial heterogeneity of these values (Figure 1). However, when we clustered the genetic distances from AMOVA using UPGMA, we observed a relatively low co-phenetic correlation of the cluster (0.59) (Figure 1), in such way that the connections of the dendrogram do not reflect correctly the multivariate genetic distance patterns. This correlation is expected for systems that do not display a very clear hierarchically structured pattern (Rodrigues and Diniz-Filho, 1998).

Table 5. $\Phi_{\mathrm{ST}}$ values among the four populations of Bothrops moojeni.

\begin{tabular}{lcccc}
\hline & 1. Sonora & 2. Minaçu & 3. Goiânia & 4. Jataí \\
\hline 1. Sonora & - & & & \\
2. Minaçu & 0.12 & - & - & - \\
3. Goiânia & 0.21 & 0.04 & 0.08 & - \\
4. Jataí & 0.24 & 0.25 & & \\
\hline
\end{tabular}




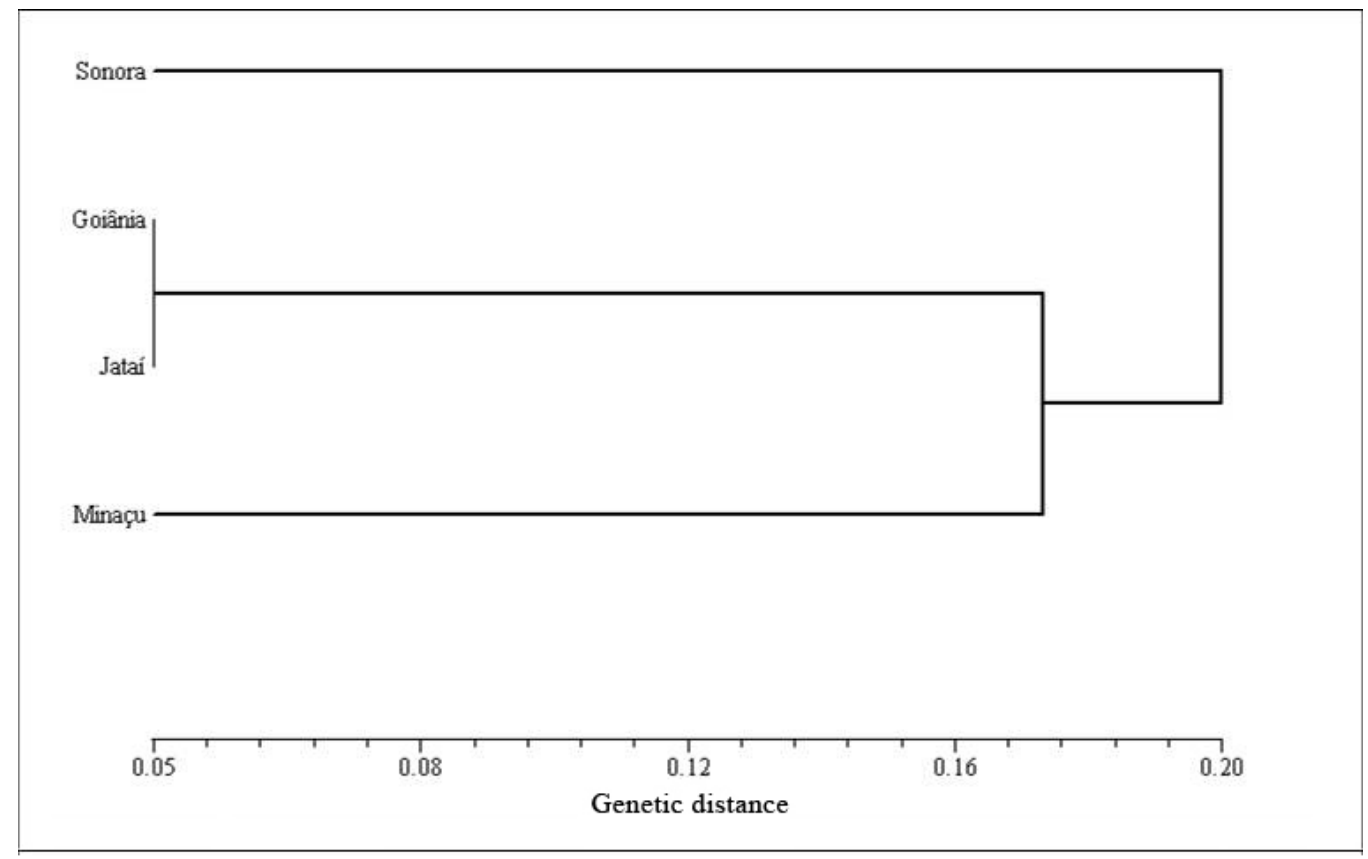

Figure 1. Genetic divergence pattern among the four populations of Bothrops moojeni, defined by the UPGMA clustering based on the genetic distances $\left(\Phi_{\mathrm{ST}}\right)$. Co-phenetic correlation equals 0.59 .

Considering the geographic scale in the present study (largest distance equal to 851.83 $\mathrm{km}$, see Table 6), some populations that are geographically closer show a significant genetic divergence (highest $\Phi_{\mathrm{ST}}$ values).

Table 6. Geographic distance $(\mathrm{km})$ among the four populations of Bothrops moojeni.

\begin{tabular}{lccc}
\hline & 1. Sonora & 2. Minaçu & 3. Goiânia \\
\hline 1. Sonora & - & & \\
2. Minaçu & 851.83 & - & - \\
3. Goiânia & 605.15 & 361.84 & 290.99 \\
4. Jataí & 343.38 & 607.87 & - \\
\hline
\end{tabular}

When we estimated the divergence among populations using the Bayesian approach (Table 7), we found that the "full model" was the one that showed the smallest DIC and Dbar $\left(\mathrm{DIC}=654.6\right.$ and $\mathrm{Dbar}=546.1$, where Dbar is the posterior mean of the deviance), with a $\theta^{\mathrm{B}}$ value equal to 0.14 . In this model, $f$ displayed a high value $(f=0.27)$. In the second best model, taking into account the parameters DIC and Dbar (values of 658.6 and 542.9, respectively), " $f=0$ ", with a $\theta^{\mathrm{B}}$ value of 0.12 . As we found similar values for both DIC and Dbar parameters in models "full" and " $f=0$ ", the proportion of genetic variation estimated among populations has two equally likely values of $\theta^{\mathrm{B}}$ around $13 \%$, similar to the one obtained with AMOVA. 


\begin{tabular}{|c|c|c|c|c|}
\hline Model & $f$ & $\theta^{\mathrm{B}}$ & Dbar & DIC \\
\hline Full & 0.27 & 0.14 & 546.1 & 654.6 \\
\hline$f=0$ & 0 & 0.12 & 542.9 & 658.6 \\
\hline$\theta^{\mathrm{B}}=0$ & 0.50 & 0 & 839.6 & 886.1 \\
\hline$f$ free & 0.51 & 0.16 & 556.9 & 672.2 \\
\hline
\end{tabular}

Dbar $=$ posterior mean of the deviance; DIC $=$ deviant information criterion.

\section{DISCUSSION}

Our two main goals were to characterize the genetic diversity in B. moojeni populations and to make an initial assessment of the genetic structure of this snake which has suffered severe habitat fragmentation by extensive agricultural practices, construction of hydroelectric plants and urbanization. Although this study does not allow the discrimination of processes of population differentiation due to "natural" processes and due to anthropic effects, it is possible to use the observed patterns of genetic diversity and population structure to delineate better conservation strategies for this species and its populations.

First, the populations analyzed showed a low level of He (0.20). Two other studies in the literature determined genetic variability using RAPD markers in snakes, but only one also showed a low value for genetic diversity $(\mathrm{He}=0.15)$, for the species Elaphe obsoleta (Prior et al., 1997; Jaggi et al., 2000). However, this value found for E. obsoleta is similar to that found in the present study $(\mathrm{He}=0.20)$. When we compare our results with those found in other studies using different markers, we see that the value is lower than the average value of 0.54 across studies (Table 8). Although we know that this comparison should be done with caution, because it considers different types of markers, variable allele number per locus and multiple spatial scale markers, it may be an initial guideline for evaluating genetic variability in natural populations of $B$. moojeni.

Table 8. List of the references of the 10 studies concerning vipers, noting different types of molecular markers
used, genetic diversity (He) and F-statistics.
\begin{tabular}{lccccc}
\hline Paper & Marker & He & F-statistics & Species & Reference \\
\hline 1 & STR & 0.53 & 0.024 & Thamnophis elegans & Manier and Arnold, 2005 \\
& STR & 0.58 & 0.035 & Thamnophis sirtalis & \\
2 & STR & 0.75 & - & Natrix natrix & Hille et al., 2002 \\
3 & RAPD & - & 0.13 & Vipera aspis & Jäggi et al., 2000 \\
4 & RAPD & 0.15 & 0.26 & Elaphe obsoleta & Prior et al., 1997 \\
5 & Isoenzymes & 0.29 & - & Vipera berus & Madsen et al., 1999 \\
& Isoenzymes & - & 0.054 & & \\
6 & STR & - & 0.036 & Thamnophis sirtalis & Bittner and King, 2003 \\
7 & STR & 0.71 & 0.006 & Nerodia sipedon sipedon & Prosser et al., 1999 \\
8 & STR & 0.53 & - & Thamnophis sirtalis & McCracken et al., 1999 \\
9 & STR & 0.70 & - & Sistrurus c. catenatus & Gibbs et al., 1997 \\
10 & Isoenzymes & 0.58 & 0.031 & Thamnophis sirtalis & Lawson and King, 1996 \\
Mean & & 0.54 & 0.072 & & \\
\hline
\end{tabular}

$\mathrm{STR}=$ short tandem repeats; RAPD $=$ random amplified polymorphic DNA. 
On the other hand, the levels of genetic structure found for B. moojeni populations using RAPDs (around 16\% by different techniques) were similar to those found for other species using the same marker. Prior et al. (1997), working with four populations of $E$. obsoleta and 15 RAPD loci, found a $\Phi_{\mathrm{ST}}$ value of 0.26 , a higher value than the one found here $\left(\Phi_{\mathrm{ST}}=0.16\right.$ and $\left.\theta^{\mathrm{B}}=0.14\right)$. However, comparing the value found for $B$. moojeni to that of other studies (see Table 8 ) with vipers which showed an average of 0.072 , we realize that this is a relatively high level of genetic structure.

The process of habitat fragmentation makes it possible for formation of habitat islands, leading the populations to evolve independently from each other and producing, as a consequence, a spatial heterogeneity of the genetic variability (high structure), like the one observed in B. moojeni populations.

Aiming at in situ conservation, in the presence of high levels of population structure, such as that found in this case, we recommend the sampling of as many populations as possible to maximize the genetic variability to be preserved. When the intention is to perform samplings toward ex situ conservation, the same should be done, sampling a large number of individuals in a great number of populations covering the entire range of the species to create a germplasm bank.

The low degree of differentiation between populations 2 (Minaçu-GO) and 3 (Goiânia-GO) is not unlikely to be observed in that spatial scale, as well as the moderate differentiation found between populations 3 (Goiânia-GO) and 4 (Jataí-GO), taking into account that these are relatively close populations, but habitat fragmentation and patterns of human activity could all be part of the cause of an obstruction of gene flow between these populations. Limited genetic differentiation between the pairs of populations 2-3 and 3-4 implies that historically these two populations have been continuous.

By contrast, we found significant divergence between populations 1 and 4 (SonoraMS and Jataí-GO, respectively) despite that they are only $361 \mathrm{~km}$ apart. Even though these populations are close to each other, they occur in an urbanized area and almost completely covered by extensive crops, representing an obstruction to the mobility of this viper. As a result, it represents a barrier to gene flow and increases levels of population structure.

The data obtained are not inconsistent if analyzed in light of the patterns of degradation by which the Cerrado's landscape has suffered throughout the years. Extensive farming predominates in the landscape of the States of Goiás and Mato Grosso do Sul. Thus, populations Sonora and Jataí are restricted to vegetation islands, which leads to the isolation of populations, making a small geographic distance very difficult to cross.

On the other hand, we identified only a moderate level of divergence between populations 1 (Sonora-MS) and 2 (Minaçu-GO). However, these two populations are more than 800 $\mathrm{km}$ apart, and between them we found the largest area of continuous and undisturbed Cerrado, so that gene flow is not unlikely to occur despite the large distance. Also, since many aspects of the ecology and life history of the species are still poorly known, the patterns of vegetation could explain the moderate divergence found. Further analyses, based on a larger sample size (i.e., number of local populations) could allow a better test of this association.

Our results show that an important component of the genetic diversity in $B$. moojeni populations may be found at the level of isolated populations. This indicates that populations 1 (Sonora-MS) and 2 (Minaçu-GO) are important for the maintenance of genetic diversity of a snake whose habitat has been severely restricted and in the case of these two populations, 
completely lost by inundation caused by the construction of a hydroelectric plant.

Habitat destruction is a major threat to the Brazilian reptile fauna and the construction of a hydroelectric power plant puts these populations at risk, for the habitat in the dam area is completely lost (Silva et al., 2005). The long-term consequences of this drastic landscape transformation such as the alteration in the inundation cycle and the upstream flow changing the deposition of sediment and disposition of sediments and nutrients are not yet clear (Pavan, 2002; Rodrigues, 2005).

Previous studies of snakes by Újvári et al. (2002) showed clear effects of habitat loss and population reduction in ecological and genetic parameters, thus supporting the notion that habitat fragmentation may lead to an increase in the effects of the small population size, such as high levels of genetic structure and inbreeding depression in the long term (Stow and Briscoe, 2005). In the present study, the potential isolation observed in B. moojeni, as a consequence of habitat disturbance and habitat loss, could become a great problem for this species.

Thus, our results suggest that the management of this species is vital to avoid or minimize the loss of genetic diversity in this threatened snake and that further studies should be conducted with urgency. This snake is one of the most abundant of the Cerrado, and preliminary studies indicate that it is well adapted to crop areas (the major habitat disturbance observed in the area of study). Taking this factor into account, we would expect to have found higher levels of genetic diversity, considering that habitat fragmentation should affect less a species well adapted to crop areas, highlighting the importance of management strategies for the conservation of $B$. moojeni.

\section{REFERENCES}

Alfenas AC (1998). Eletroforese de isoenzimas e proteínas afins: fundamentos e aplicações em plantas e microrganismos. Universidade Federal de Viçosa, Viçosa.

Beebee T and Rowe G (2004). An Introduction to Molecular Ecology. Oxford University Press, Oxford.

Bittner TD and King RB (2003). Gene flow and melanism in garter snakes revisited: a comparison of molecular markers and island vs. coalescent models. Biol. J. Linn. Soc. 79: 389-399.

Campbell JA and Lamar WW (2004). Venomous Reptiles of the Western Hemisphere. Cornell University Press, New York. Epperson BK (2003). Geographical Genetics. Princeton University Press, New Jersey.

Excoffier L, Smouse PE and Quattro JM (1992). Analysis of molecular variance inferred from metric distances among DNA haplotypes: application to human mitochondrial DNA restriction data. Genetics 131: 479-491.

Frankham RJ, Ballou D and Briscoe DA (2003). Introduction to Conservation Genetics. Cambridge University Press, Cambridge.

Frankhan R, Ballou J, Briscoe D and McInnes KH (2004). A Primer of Conservation Genetics. Cambridge University Press, Cambridge.

Galinkin M (2003). GeoGoiás: Estado Ambiental de Goiás 2002. Fundação CEBRAC: PNUMA:SEMARH, Goiânia.

Gibbs HL, Prior KA, Weatherhead PJ and Johnson G (1997). Genetic structure of populations of the threatened eastern massasauga rattlesnake, Sistrurus c. catenatus: evidence from microsatellite DNA markers. Mol. Ecol. 6: 1123-1132.

Hartl DL (2000). A Primer of Population Genetics. Sinauer Associates, Sunderland.

Hille A, Janssen IA, Menken SB, Schlegel M, et al. (2002). Heterologous amplification of microsatellite markers from colubroid snakes in European natricines (Serpentes: Natricinae). J. Hered. 93: 63-66.

Holsinger KE (1999). Analysis of genetic diversity in geographically structured populations: a Bayesian perspective. Hereditas 130: 245-255.

Holsinger KE and Lewis PO (2003). Department of Ecology and Evolutionary Biology. University of Connecticut, Connecticut. Available at http://www.eeb.uconn.edu/.

Holsinger KE and Wallace LE (2004). Bayesian approaches for the analysis of population genetic structure: an example from Platanthera leucophaea (Orchidaceae). Mol. Ecol. 13: 887-894. 
Holsinger KE, Lewis PO and Dey DK (2002). A Bayesian approach to inferring population structure from dominant markers. Mol. Ecol. 11: 1157-1164.

IBAMA (2003). Lista das espécies da fauna brasileira ameaçadas de extinção. Instrução normativa No. 03 de 27 de maio de 2003. IBAMA, Brasília.

Jäggi C, Wirth T and Baur B (2000). Genetic variability in subpopulations of the asp viper (Vipera aspis) in the Swiss Jura mountains: implications for a conservation strategy. Biol. Conserv. 94: 69-77.

Klink C and Machado RA (2005). Conservation of the Brazilian Cerrado. Conserv. Biol. 19: 707-713.

Lawson R and King RB (1996). Gene flow and melanism in Lake Erie garter snake populations. Biol. J. Linnean Soc. 59: 1-19.

Lynch M and Milligan BG (1994). Analysis of population genetic structure with RAPD markers. Mol. Ecol. 3: 91-99.

Madsen T, Stille B and Shine R (1996). Inbreeding depression in an isolated population of adders Vipera berus. Biol. Conserv. 75: 113-118.

Madsen T, Olsson M, Shine R and Wittzell H (1999). Genetical restoration of an inbred populations of adder (Vipera berus). Nature 402: 34-35.

Manier MK and Arnold SJ (2005). Population genetic analysis identifies source-sink dynamics for two sympatric garter snake species (Thamnophis elegans and Thamnophis sirtalis). Mol. Ecol. 14: 3965-3976.

Manly BFJ (1986). Multivariate statistical methods: a primer. Chapman and Hall, London.

Manly BFJ (1997). Randomization, Bootstrap and Monte Carlo Methods in Biology. 2nd edn. Chapman and Hall, London.

McCracken GF, Burghardt GM and Houts SE (1999). Microsatellite markers and multiple paternity in the garter snake Thamnophis sirtalis. Mol. Ecol. 8: 1475-1479.

Miller MP (1997). Tools for populations genetic analyses (TFPGA) 1.3. A windows program for analysis of allozyme and molecular populations genetic data. [Computer software distributed by author].

Nei M (1973). Analysis of gene diversity in subdivided populations. Proc. Natl. Acad. Sci. U. S. A. 70: 3321-3323.

Nogueira C, Sawaya RJ and Martins M (2003). Ecology of the Pitviper, Bothrops moogeni, in the Brazilian Cerrado. J. Herpetol. 37: 653-659.

Pavan D (2002). Considerações ecológicas sobre a fauna de sapos e lagartos de uma área do Cerrado Brasileiro sob o impacto do enchimento do reservatório de Serra da Mesa. M.S. thesis, Universidade de São Paulo, São Paulo.

Petit JR, Mousadik AE and Pons O (1998). Identifying populations for conservation on the basis of genetic markers. Conserv. Biol. 12: 844-855.

Prior KA, Gibbs HL and Weatherhead PJ (1997). Population genetic structure in the black rat snake: implications for management. Conserv. Biol. 11: 1147-1158.

Prosser MR, Gibbs HL and Weatherhead PJ (1999). Microgeographic population genetic structure in the northern water snake, Nerodia sipedon sipedon detected using microsatellite DNA loci. Mol. Ecol. 8: 329-333.

Rodrigues FM and Diniz-Filho JAF (1998). Hierarchical structure of distances: effects of matrix size, spatial distribution and correlation structure among gene frequencies. Genet. Mol. Biol. 21: 233-240.

Rodrigues MT (2005). The conservation of Brazilian reptiles: challenges for a megadiverse country. Conserv. Biol. 6: 659-664.

Silva NJ, Silva HLR, Rodrigues MTU, Valle NC, et al. (2005). A fauna de vertebrados do vale do alto rio Tocantins em áreas de usinas hidrelétricas. Estudos, Goiânia 32: 57-101.

Smouse PE, Long JC and Sokal RR (1986). Multiple regression and correlation extensions of the Mantel test of matrix correspondence. Syst. Zool. 35: 627-632.

Spiegelhalter DJ, Spiegelhalter DJ, Best NG and van der Linde A (2002). Bayesian measures of model complexity and fit. J. R. Stat. Soc. B 64: 483-689.

Stow AJ and Briscoe DA (2005). Impact of habitat fragmentation on allelic diversity at microsatellite loci in Cunningham's skink (Egernia cunninghami): a preliminary study. Conserv. Genet. 6: 455-459.

Telles MPC, Diniz Filho JAF, Bastos RP, Soares TN, et al. (2007). Landscape genetics of Physalaemus cuvieri in Brazilian Cerrado: correspondence between population structure and patterns of human occupation and habitat loss. Biol. Conserv. 139: 37-46.

Újvári B, Madsen T, Kotenkod T, Olssone M, et al. (2002). Low genetic diversity threatens imminent extinction for the Hungarian meadow viper (Vipera ursinii rakosiensis). Biol. Conserv. 105: 127-130.

Weir BS (1996). Genetic Data Analysis II. Sinauer Associates, Sunderland. 